\title{
PRINCÍPIOS E MÉTRICAS PARA AVALIAÇÃO DO DOT ${ }^{1}$
}

\author{
Fernando Tadeu de Araujo Lima² \\ Nuno Montenegro 3 \\ Rodrigo Cury Paraizo 4 \\ José Ripper Kós ${ }^{5}$
}

DOI: $10.5752 / P .2316-1752.2020 v 27 n 40 p 243$

\section{Resumo}

O Desenvolvimento Orientado pelo Transporte (DOT) é um modelo de desenvolvimento urbano que preconiza cidades mais sustentáveis. Este artigo tem por objetivo identificar e apresentar métricas para avaliação de desempenho que se relacionam com seus princípios básicos, de natureza objetivamente mensurável. Pretende-se, portanto, contribuir para abordagens de análise e proposição que possam ser suportadas pela implementação

\footnotetext{
1. Artigo elaborado a partir da tese de LIMA, F.T.A., intitulada "MÉTRICAS URBANAS: Sistema (para)métrico para análise e otimização de configurações urbanas de acordo com métricas de avaliação de desempenho." Universidade Federal do Rio de Janeiro, 2017.

2. Arquiteto pela UFJF, doutor em urbanismo pela UFRJ. Professor do Departamento de Projeto, Representação e Tecnologia da FAU-UFJF. E-mail: fernando.lima@arquitetura.ufjf.br

3. Arquiteto pela ULisboa, doutor em Urbanismo pela ULisboa. Professor da Faculdade de Arquitetura da ULisboa. E-mail: nunomontenegro@mail.com

4. Arquiteto pela UFRJ, doutor em urbanismo pela UFRJ. Professor do Departamento de Análise e Representação da Forma da FAU-UFRJ. E-mail: rparaizo@gmail.com.

5. Arquiteto pela UFRJ, PhD em Tecnologia da Informação e Arquitetura, pela University of Strathclyde. Professor do Departamento de Arquitetura e Urbanismo da UFSC. E-mail: jose.kos@ ufsc.br
} 
instrumental dos princípios e das métricas aqui caracterizadas.

Palavras-chave: Desenvolvimento Orientado Pelo Transporte. Métricas urbanas. Caminhabilidade. Diversidade de usos. Compacidade. 


\section{PRINCIPLES AND METRICS FOR TOD ASSESS- MENT}

\begin{abstract}
Transit-Oriented Development is an urban development model aimed at more sustainable cities. This article aims to identify and present metrics for performance evaluation of this model's fundamental principles of an objectively measurable nature. Therefore, it is intended to contribute to the discussion on the subject and promote analysis and urban propositions that can be supported by an instrumental implementation of the principles and metrics described here.
\end{abstract}

Keywords: Transit-Oriented Development. Urban metrics. Walkability. Land-use diversity. Compactness.
PRINCIPIOS Y MÉTRICAS PARA LA EVALUACIÓN DOT

\section{Resumen}

El Desarrollo Orientado al Transporte (DOT) es un modelo de desarrollo urbano que aboga por ciudades más sostenibles. Este artículo tiene como objetivo identificar y presentar métricas para la evaluación del desempeño que estén relacionadas con sus principios básicos, de naturaleza objetivamente medible. Se pretende, por tanto, contribuir a enfoques de análisis y proposición que puedan apoyarse en la implementación instrumental de los principios y métricas aquí caracterizados.

Palabras-claves: Desarrollo Orientado al Transporte. Métricas urbanas. Transitabilidad. Diversidad de usos. Compacidade. 


\section{Introdução}

A queima de combustíveis fósseis em veículos motorizados tem sido responsabilizada por até 75 por cento da poluição do ar nos centros urbanos e foi associada a 3,7 milhões de mortes prematuras em 2012 (Global Fuel Economy, 2016). Além de contribuir para as emissões de carbono, o paradigma de organização e de expansão das cidades tem causado grandes impactos inconvenientes nos centros urbanos contemporâneos (e. g. dependência do automóvel, padrões espaciais fragmentados, menor interação social). Nesse cenário, o Desenvolvimento Orientado pelo Transporte (DOT) se tornou um dos principais modelos de planejamento destinados à criação de bairros compactos, caminháveis e de uso misto, organizados em torno de estações de transporte. Essa lógica de organização de configurações urbanas incentiva a criação de comunidades que não dependem exclusivamente do automóvel para os deslocamentos diários e está sendo crescentemente promovida em várias cidades do mundo como exemplo de uma prática mais sustentável para a organização de bairros e centros urbanos (FARR, 2013; LEITE, 2012; SUZUKI; CERVERO; IUCHI, 2013).

Além disso, é possível identificar princípios básicos do DOT que podem ser aferidos por meio de diversas métricas, de natureza geométrica, algébrica e mensurável (LIMA, 2017; LIMA; KÓS; PARAíZO, 2016a; LIMA; PA- 
RAÍZO; KÓS, 2016b). No entanto, há forte demanda por métodos ou sistemas que auxiliem os atores envolvidos na discussão, proposição e/ou avaliação de projetos baseados na lógica do DOT a serem implementados de maneira mais bem-sucedida (PATEL; SHAH, 2019; SUZUKI; CERVERO; IUCHI, 2013; LEITE, 2012).

Portanto, este artigo visa identificar e apresentar métricas para avaliação do DOT, que se relacionam com seus princípios básicos de natureza objetivamente mensurável. Portanto, a seção 2 deste paper traz uma revisão de literatura do DOT, delineando seu conceito, suas definições, vantagens, limitações e a sua relevância. A seção 3 apresenta uma identificação dos princípios básicos do DOT e suas características objetivamente mensuráveis, enquanto a seção 4, estabelece métricas que podem ser utilizadas para mensurar o atendimento de uma área urbana (ou de eventuais propostas) a cada um destes princípios. Na seção final, se discute sobre o potencial da utilização dessas métricas em processos de planejamento orientado pelo DOT.

\section{DOT - Conceitos e definições, vantagens, li- mitações e relevância.}

\subsection{Conceito e definições}

Peter Calthorpe (1993), em seu livro intitulado "The next american metropolis" ", iniciou a articulação de algumas 
premissas de planejamento urbano sustentável, que posteriormente vieram a constituir as bases do conceito do Transit Oriented Development, no original em inglês, ou Desenvolvimento Orientado pelo Transporte, como é comumente traduzido para o português. São elas: i) a organização do crescimento a um nível regional, de maneira policêntrica e compacta, que ofereça suporte à mobilidade urbana; ii) o posicionamento de residências, pontos de comércio e emprego, parques e demais usos dentro de uma distância acessível a pé das paradas de trânsito; iii) a criação de redes de vias que conectem destinos locais e que incentivem a caminhada e o ciclismo; iv) a promoção de um mix de densidades, tipologias e usos; v) a preservação do habitat local, zonas ribeirinhas e espaços abertos e de alta qualidade; vi) a instituição dos espaços públicos como foco para a orientação dos edifícios e das atividades da vizinhança e; vii) o incentivo à ocupação e ao desenvolvimento ao longo de corredores de trânsito e comunidades existentes.

Atualmente, entretanto, embora não exista uma definição consensual para o DOT, ele é frequentemente descrito de uma maneira física: uma área compacta com edifícios de uso misto, que conecta serviços e residências por meio de distâncias caminháveis e servida por uma rede de mobilidade multimodal (CALTHORPE; FULTON, 2001; CERVERO; KOCKELMAN, 1997; SUZUKI; CERVERO; IUCHI, 2013). Nesse modelo, necessidades urbanas básicas são 
facilmente acessíveis sem exigir automóveis ou despender grandes quantidades de tempo em deslocamentos, suportando bairros mais autônomos e sustentáveis.

Adotar esse modelo de desenvolvimento urbano significa considerar um novo paradigma para o funcionamento e para o próprio metabolismo das cidades. Uma implementação adequada do DOT requer que a estruturação urbana, a lógica de transporte e a configuração das vias, dos passeios e das quadras se deem de maneira diferente do que preconiza o modelo de desenvolvimento urbano comumente adotado. Stuchi e Leite (2015) apontam também que para se conseguir cidades articuladas e agradáveis é necessário desprestigiar o modelo de desenvolvimento ligado ao automóvel particular e estimular os usos de transportes alternativos, conjuntamente à intensificação do uso e qualificação do transporte coletivo.

Para Gehl (2013), o DOT é um modelo de desenvolvimento urbano de crescente aceitação em todo o mundo, que compreende a concentração nas "interrelações entre as estruturas para pedestres e ciclistas e a rede coletiva de tráfego" (Gehl, 2013, p.107). Além disso, Gehl (2013) considera uma vantagem o fato de que cidades compactas baseadas no DOT são capazes de oferecer um número suficiente de moradias e locais de trabalho a uma distância caminhável das estações. Essas cidades, com bons espaços públicos e curtas distâncias entre trabalho, 
serviços e moradias "garantem inúmeras vantagens ambientais como linhas de abastecimento curtas e reduzido consumo de áreas." (GEHL 2013) p. 107).

Farr (2013), por sua vez, apresenta o DOT como um modelo de organização urbana que proporciona mais opções de habitação e transporte, além de serviços variados que podem ser acessados a pé (priorização dos pedestres e vida urbana). Em paralelo, Dittmar e Ohland (2004) entendem que o DOT visa maximizar o acesso ao transporte coletivo e não motorizado, por meio da implantação de estações (de trem ou ônibus) centralmente localizadas e rodeadas por densidade relativamente alta.

Ainda segundo Farr (2013), o DOT transcende a ideia de simplesmente se orientar uma unidade de vizinhança próxima a uma estação de transporte público. Trata-se, no entanto, do conceito de um bairro estruturado em torno de uma estação ou ao longo de um corredor de transporte, permeado por empreendimentos múltiplos, usos mistos, e "uma rede viária em que se possa caminhar e um desenho que permita vida urbana e opções de transporte." (FARR. 2013, p. 109).

Suzuki, Cervero e luchi (2013) consideram o DOT uma abordagem prática para reduzir congestionamento, emissão de gases responsáveis pelo efeito estufa e outros causadores de problemas ambientais, além de proporcio- 
nar possibilidades de arranjo e organização espacial urbana que visam a promover maior interação social, melhor uso do solo e conexões entre trabalho, serviços e residências. Ainda segundo Suzuki, Cervero e luchi (2013), experiências mostram que a implementação bem-sucedida do DOT não apenas aumenta o uso do transporte coletivo (estimulando usuários a abandonarem os carros e utilizarem ônibus ou trens), mas também serve como instrumento para o desenvolvimento das comunidades e revitalização de bairros deteriorados.

Há certo consenso, segundo os autores apresentados de que determinados atributos ou princípios do DOT, são especialmente benéficos para a estruturação e o funcionamento dos centro urbanos contemporâneos. Embora nem todos mencionem especificamente o DOT (pois o termo específico e o conceito surgiram a posteriori mediante uma certa "concatenação" de ideias) os autores estudados defendem a implementação dessa "lógica" de organização e desenvolvimento urbano como um importante passo na direção de cidades mais autônomas, integradas, caminháveis e sustentáveis. Nesse cenário, é possível apontar algumas vantagens e limitações desse modelo de desenvolvimento urbano, conforme em sequência. 


\subsection{Vantagens e limitações}

Dentre as vantagens apontadas à adoção do DOT como modelo para estruturação e organização espacial dos centros urbanos, encontram-se: a) a redução da emissão de gases poluentes do ar e de gases relacionados ao efeito estufa; b) a promoção de comunidades caminháveis, que incentivam modos de vida mais saudáveis e menos sedentários; c) a otimização de infraestrutura urbana, uma vez que a expansão da urbanização demanda maiores custos públicos com a provisão e manutenção da infraestrutura e serviços urbanos e; d) a redução da dependência do automóvel (FARR, 2008; STUCHI; LEITE, 2015; SUZU$\mathrm{KI}$; CERVERO; IUCHI, 2013).

Apesar de todos esses benefícios relacionados, o DOT ainda apresenta algumas limitações que dificultam sua implementação com maior frequência e eficiência. Diversos autores permitem encontrar, basicamente, limitações de quatro ordens a esse respeito. São elas: a) de ordem financeira - apesar de reduzir custos com infraestrutura a longo prazo, o DOT demanda grandes investimentos públicos e privados para ser implantado; b) de ordem participativa - resistências da comunidade local representam um desafio para a implementação do DOT, uma vez que moradores muitas vezes temem que o DOT possa descaracterizar seu bairro, criar congestionamento de tráfego localizado ou depreciar suas propriedades; c) de ordem 
legal - a legislação da maioria dos municípios não é favorável à implantação do DOT, pois leis de zoneamento e códigos de uso do solo são geralmente concebidos para a lógica de bairros e edifícios monofuncionais, com desenvolvimento orientado aos automóveis. Em alguns casos, parâmetros de zoneamento frequentemente proíbem a densidade necessária, e disposições como valores máximos em relação a taxa de ocupação, limitações de altura e afastamentos dos edifícios, entre outros, praticamente inviabilizam o DOT, apesar de serem comumente distorcidos por interesses relativos à especulação imobiliária e; d) de ordem instrumental - ainda não foram suficientemente desenvolvidos instrumentos ou sistemas que auxiliem os atores envolvidos na discussão, proposição e/ou avaliação de projetos, a implementarem de maneira eficiente soluções baseadas na lógica do DOT (DITTMAR; OHLAND, 2004; STUCHI; LEITE, 2015; SUZUKI; CERVERO; IUCHI, 2013). Portanto, torna-se de grande importância a elaboração de instrumentos e/ou ferramentas de suporte a tarefas de suporte à tomada de decisão, bem como a identificação de métricas para avaliação de implementação do DOT. Há que se ressaltar, ainda, que esses obstáculos para a implementação do DOT são acentuados no contexto brasileiro, principalmente em áreas urbanas periféricas, que são as mais impactadas pelas dificuldades de transporte e baixa acessibilidade aos serviços. 


\subsection{Relevância}

Para Leite (2012), há uma forte demanda atual em promover cidades providas de um metabolismo que gere maior urbanidade, o que Gehl (2013) define como "cidades para as pessoas". Ogra e Ndebele (2014) afirmam que o DOT assumiu, nos últimos anos, um papel central no contexto das políticas de mobilidade urbana mundial, tornando-se um dos principais paradigmas de planejamento que visa a reverter o desenvolvimento urbano baseado nos deslocamentos por automóvel individual. Em consonância, Dittmar e Ohland (2004) afirmam que o DOT vem sendo crescentemente promovido em várias cidades do mundo como uma política sustentável para centros urbanos contemporâneos.

Segundo a Transit Cooperative Research Program (2004), uma entidade norte-americana voltada para a pesquisa sobre mobilidade urbana, uma grande variedade de DOTs pode ser encontrada no Estados Unidos e todos os indicadores demonstram que os números e tipos de DOT tendem a aumentar naquele país. Atualmente, existe mais de uma centena de DOTs implementados nos Estados Unidos, em diversas escalas e tipologias. Altoon e Auld (2011) demonstram que a relevância do DOT não se restringe aos Estados Unidos e apresentam inciativas de implementação do DOT em diversos países como: Alemanha, Austrália, Bélgica, Canadá, China, França, Ho- 
landa, Nova Zelândia, Polônia, Reino Unido, Rússia, entre outros.

No Brasil, cujo tempo médio de deslocamento nas regiões metropolitanas aumentou de 38,1 para 43,3 minutos nos últimos 10 anos (RODRIGUES, 2016), há uma flagrante saturação dos meios de transporte existentes e uma crescente demanda por soluções para esse desafio em cidades de grande e médio porte, principalmente. Pode-se observar, nos últimos anos, a implementação de BRTs (Bus Rapid Transit) em diversos centros urbanos brasileiros (sendo a cidade de Curitiba uma das pioneiras). A cidade de Nova Friburgo, por sua vez, ao elaborar seu Plano de Desenvolvimento Urbano Estratégico - 2050, estabeleceu princípios do DOT como parte da estratégia central para aproximar as atividades da cidade, qualificar a vida urbana nos bairros, equilibrar as dinâmicas urbanas e alinhar desenvolvimento urbano e mobilidade, ao incentivar a criação de territórios compactos e de redes de centralidades multifuncionais, em "uma rede equilibrada de núcleos densos conectados por adequados sistemas de mobilidade" (STUCHI; LEITE, 2015, p. 24).

O município de São Paulo, por outro lado, apesar de não citar nominalmente o conceito do DOT, incorpora muitas de suas premissas (e. g. priorizar o uso do transporte público, valorizar o pedestre e seus percursos, implementar múltiplos modais, incentivar o uso misto e a multicentra- 
lidade, distribuir equilibradamente serviços urbanos ao longo dos bairros e orientar o crescimento da cidade nas proximidades do transporte público) na elaboração de seu Plano Diretor Estratégico (SÃO PAULO, 2014).

\section{Princípios mensuráveis do DOT}

Em trabalhos anteriores afirmamos que o DOT é um modelo de desenvolvimento urbano que considera princípios mensuráveis (e, portanto, programáveis) para melhorar o desempenho sustentável de bairros e centros urbanos sob a perspectiva da mobilidade urbana e do uso do solo solo (LIMA. 2017; LIMA et al. 2016a; LIMA et al. 2016b). Baseado nisso e considerando o universo de interesse e o escopo desta pesquisa, é possível estabelecer parâmetros-chave que permitam avaliar configurações urbanas ${ }^{6}$ sob a perspectiva dos princípios do DOT. As premissas fundamentais que estruturam o conceito do DOT variam de acordo com algumas definições, mas em essência, podem ser mensuradas por meio de características ou

6. Para efeito desta pesquisa, são considerados como configurações urbanas os seguintes arranjos formais (geométricos e algébricos) do espaço urbano, relacionados à organização de bairros e cidades sob a perspectiva da mobilidade urbana e do uso do solo: o desenho de ruas, quadras, lotes e edifícios; a distribuição, a variedade e a localização de serviços urbanos e suas respectivas distâncias para as demais localidades de um bairro; a articulação e a proporção entre áreas residenciais e não residenciais desse mesmo bairro; atributos diretamente relacionados à densidade, como indicadores de aproveitamento construtivo e de ocupação do solo. 
propriedades objetivas como: distância física ${ }^{7}$; distância topológica ${ }^{8}$; densidade física; densidade populacional; contagem/posicionamento de equipamentos urbanos, entre outros. Nesta pesquisa, as premissas apresentadas anteriormente, são articuladas por meio de quatro princípios básicos, que visam a permitir a quantificação e a análise de características fundamentais do DOT, são eles: a) a acessibilidade ao transporte; b) a caminhabilidade; c) a diversidade e; d) a compacidade.

\subsection{Acessibilidade ao transporte}

Promover curtas distâncias até o acesso ao transporte público significa conectar melhor a cidade, incentivar a caminhada, o ciclismo e a utilização do sistema de transporte público. A distância possui implicações substanciais para a viabilidade e a eficácia de um sistema de transporte público: em essência, a distância permite mensurar a proximidade ou a acessibilidade ${ }^{9}$ de uma estação de trânsito

\footnotetext{
7. O termo "distância física", no contexto desta pesquisa, refere-se àquela dada (em metros, por exemplo) pelo menor caminho disponível para conectar duas localidades e não necessariamente pela linha reta entre dois pontos, isto é, a distância física é dada pela distância percorrida para se alcançar um ponto $B$, partindo de um ponto $A$, dada uma rede " $R$ " de ruas para deslocamento. 8. O termo "distância topológica" é aqui utilizado no mesmo sentido daquele proposto na teoria da sintaxe espacial, proposta por Hillier e Hanson (1984), ou seja: o número de ruas (ou de mudanças de direção) necessárias para se alcançar um determinado destino.

9. O termo "acessibilidade" é aqui adotado, de maneira mais restrita, como aquele que se refere à proximidade (física ou topológica) entre dois ou mais pontos e não necessariamente como forma de designar a disciplina que busca promover o acesso de pessoas portadoras de algum tipo de deficiência ou mobilidade reduzida.
} 
Entretanto, frequentemente, os esforços em tornar as cidades mais conectadas têm tido como premissa a opção por proporcionar a movimentação de pessoas ao redor da cidade mais rapidamente, com a abertura de uma quantidade cada vez maior de vias para deslocamento de automóveis, e não por trazer os serviços urbanos mais próximos das pessoas. A este respeito, Calthorpe (1993) pontua que os sistemas de transporte precisam ser estruturados de maneira a facilitar o acesso a uma grande variedade de destinos, como trabalho, serviços, recreação, entre outros.

Nesse contexto, a acessibilidade ao transporte é um princípio fundamental dentro da equação do DOT e uma questão importante para esta pesquisa, uma vez que preconiza a proximidade (física e/ou topológica) entre a estação e/ou paradas de transporte e os locais de moradia, trabalho e demais destinos de uma área urbana. É importante considerar também, que conferir uma boa acessibilidade ao transporte significa potencializar o acesso de todas as classes sociais às oportunidades ofertadas pelas cidades.

\subsection{Caminhabilidade}

Gehl (2013) defende que a cidade tende a se tornar mais viva, na medida em que mais pessoas se sintam convi- 
dadas a caminhar, pedalar ou permanecer nos espaços públicos, interagindo e trocando informações e oportunidades sociais e culturais. Caminhar por um bairro que possua parques, serviços e comércios que estejam diretamente conectados a uma pequena distância é, sem dúvida, uma atividade muito mais agradável que andar por regiões onde esses se encontram dispersos, o que tende a trazer mais pessoas para o convívio no espaço urbano.

Para Farr (2013), a caminhabilidade consiste na capacidade que um determinado bairro possui de conectar habitações, pontos de comércio e demais serviços por meio de distâncias que podem ser percorridas a pé, conferindo, assim, maior autonomia, menor dependência do automóvel e "uma rede viária em que se possa caminhar e um desenho que permita vida urbana e opções de transporte" (Farr, 2013, p.109). Nesse sentido, o princípio da caminhabilidade, no contexto desta investigação, é aquele que preconiza a organização do espaço urbano em função de promover as menores distâncias possíveis ${ }^{10}$ aos inúmeros serviços que um bairro estruturado na lógica do DOT deve possuir.

10. Evidentemente, quanto menor for a distância entre as localidades de um bairro e seus serviços, maiores serão os índices de caminhabilidade. No entanto, há certo consenso de que distâncias de até $400 \mathrm{~m}$ são consideradas como ideais. Há que se considerar também, que no contexto atual, de desenvolvimento rápido das tecnologias de transporte, a distância muitas vezes pode ser substituída pelo tempo, como métrica de avaliação da acessibilidade, sobretudo em espaços menos densos. 
No caso específico da caminhabilidade, as análises ganham contornos mais complexos quando comparadas ao cálculo da acessibilidade ao transporte. Isso porque aqui interessa avaliar não apenas a distância para um equipamento único (no caso da acessibilidade ao transporte a estação), mas sim verificar qual o nível de acesso a diferentes serviços essenciais à vida nas cidades, o que significa abordar: a) quais categorias de serviços estão disponíveis em uma determinada vizinhança (e. g. educação, comércio, alimentação, recreação, entre outros); b) qual a proximidade dos serviços em cada uma dessas categorias (considerando distâncias físicas e topológicas); c) qual a diversidade dessas categorias, uma vez que cada uma delas engloba diferentes atividades (no caso da educação, por exemplo, creches, escolas e faculdades desempenham papeis diferentes, mas igualmente importantes para a dinâmica de um bairro), e; d) qual a quantidade desstes serviços em cada categoria, o qual possui correspondência direta com as opções disponíveis em uma determinada área urbana.

\subsection{Diversidade}

Calthorpe (1993) entende que o uso diversificado na escala do bairro é um fator primordial para a sustentabilidade das cidades e por isso reforça a importância de vizinhanças multifuncionais. Rogers (1997) defende o uso misto e a diversidade para um melhor aproveitamento de 
espaços, a partir de uma lógica em que tudo acontece simultaneamente: morar, trabalhar, consumir e recrear em uma mesma área, visando atender o princípio de posicionar serviços e comércios sem a necessidade de grandes deslocamentos. Sendo assim, bairros configurados com diversos tipos de serviços que se complementem, incentivam as pessoas a deslocarem-se a pé, por meio da proximidade de diferentes serviços necessários no cotidiano, permitindo o contato e a integração de pessoas de diferentes culturas e classes, e potencializando a qualidade de interação e de vida social. Panerai, Castex e Depaule (2013) defendem que a questão do tecido urbano não pode ser dissociada da experiência cotidiana da cidade.Nessa ótica, ressaltam ainda, a importância de ações sustentáveis no projeto urbano como um espaço público acessível a todos, com vizinhanças mistas, atividades que se misturem e edifícios que se adaptem e se transformem.

O princípio da diversidade, no contexto desta investigação, é aquele que preconiza a distribuição equilibrada entre as áreas residenciais e as não residenciais em uma mesma vizinhança. Quanto mais equilibrada for esta relação, menor a quantidade de grandes deslocamentos tende a ser, o que significa bairros mais autônomos e sustentáveis. Esse princípio, também fundamental para o conceito do DOT, atende à premissa da cidade polinucleada com centralidades multifuncionais, isto é, defende 
que todos os serviços essenciais à vida urbana estejam acessíveis dentro de um bairro por meio de distâncias caminháveis, ou ainda, bem como por meio de transportes coletivos e integrados que permitam acesso a outros bairros, igualmente diversos e caminháveis.

\subsection{Compacidade}

A compacidade em áreas urbanas é uma ideia defendida por diversos autores, como Dantzig e Saaty, (1973); Rogers, (1997); Gaeser, (2011); Leite,( 2012); Chakrabarti, (2013) ; Farr, (2008); Gehl, (2013); Suzuki, Cervero e luchi, (2013). Rogers (1997), por sua vez, afirma que cidades sustentáveis são compactas, pois a cidade compacta propicia otimizar o desempenho de energia, reduzir o nível de poluição e o consumo de recursos, além de oferecer as vantagens de se morar próximo ao local de trabalho e do outro, em uma busca pela redescoberta da proximidade.

Segundo Stuchi e Leite (2015), a noção de cidade compacta se sustenta em três pilares: a otimização de recursos, a inovação e a sustentabilidade. A otimização de recursos se dá à medida em que "maiores densidades urbanas potencializam as infraestruturas urbanas, as ruas e os sistemas de transporte, redes de cabos ou fibras e equipamentos públicos" (STUCHI; LEITE, 2015, p. 30). Além de aproximar pessoas e suas necessidades urbanas, cidades mais compactas desperdiçam menos inves- 
timentos públicos. A inovação acontece, porque cidades compactas "propiciam concentração de diversidade que gera inovação e oportunidades únicas (seja em termos de conhecimento, cultura ou desenvolvimento econômico)." (STUCHI; LEITE, 2015, p. 30).

Maiores densidades promovem o encontro, a diversidade e otimizam o uso de infraestruturas urbanas e recursos públicos, além de determinarem menores consumos (principalmente de recursos energéticos) per capita e menor produção de resíduos e de gases de efeito estufa, ou seja, "cidades compactas são mais sustentáveis." (STUCHI; LEITE, 2015, p. 31). Para Rogers (1997), a cidade compacta, mais que ser sustentável, promove maior autonomia às áreas urbanas, abrigando atividades diversas que, ao mesmo tempo, se complementam e sobrepõem. Para Leite (2012), "a opção pelos parâmetros advindos da cidade compacta tem sido consenso internacional." (LElTE, 2012, p. 135).

Conforme mencionado anteriormente, um desafio crítico voltado para aqueles que pensam e planejam a cidade é o alto nível de dependência do automóvel. Desenvolvimentos de baixa densidade têm influência direta nesta questão. Assim, Ogra e Ndebele (2014) apontam que as áreas urbanas devem ser concebidas de maneira a suportar desenvolvimentos de alta densidade, complementados por uso do solo misto e investimentos em sistemas de trans- 
portes públicos. A esse respeito, altas densidades estão normalmente relacionadas a menores distâncias médias de viagem para todos os modais. A principal premissa do desenvolvimento de alta densidade assume que a colocação de edifícios residenciais perto de grandes nós de transporte, instalações e locais de trabalho irá aumentar a conveniência e, portanto, a aceitação de modos de transporte sustentáveis.

Neste contexto, a compacidade é um princípio fundamental na lógica do DOT, uma vez que preconiza o adensamento de áreas urbanas por meio da verticalização e da concentração de atividades e equipamentos. Instrumentos para mensurar diferentes aspectos da densidade de uma área urbana são indispensáveis para articular relações entre os serviços disponíveis, os modais de transportes e a quantidade potencial de pessoas que podem residir e trabalhar em uma determinada localidade. 


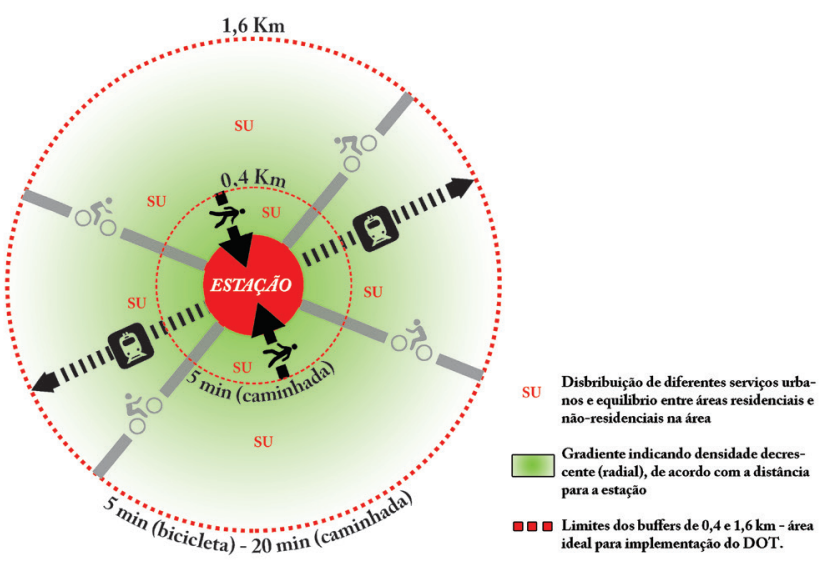

Figura 1 | Diagrama conceitual dos princípios básicos mensuráveis do DOT. Fonte: Os autores, adaptado de Lima, 2017, p. 62.

\section{Métricas para avaliação de princípios básicos do DOT}

\subsection{Métricas para a acessibilidade ao transporte}

A acessibilidade ao transporte de uma determinada área pode ser aferida por meio do cálculo da distância dos menores percursos entre uma determinada estação e sua área de influência (ou bairro). Importa, sob essa noção, mensurar a distância física para a estação, considerando as inclinações no percurso, mas também a distância topológica, ou seja: o número de ruas (ou de mudanças de 
direção) necessárias para se alcançar um destino. Assim, quanto menores as distâncias físicas e topológicas entre todos os destinos de uma determinada localidade e sua respectiva estação, maior a acessibilidade ao transporte deste bairro.

Gehl (2013, p. 121) afirma que "a distância aceitável de caminhada é um conceito relativamente fluido" e que fatores como a qualidade do percurso, a superfície, a quantidade de pessoas e os obstáculos no trajeto influenciam este dado. Entretanto, o próprio Gehl (2013, p. 121) reconhece a necessidade de estabelecer uma meta para deslocamentos a pé ao afirmar que "o tamanho dos centros das cidades confirma a distância de 500 metros como um objetivo aproximado de uma caminhada aceitável."

Em concordância com o valor aceitável para Gehl, um valor de referência comumente aceito para estabelecer a distância ideal para uma estação de transporte é o de cinco minutos (ou menos) de deslocamento. Para distâncias percorridas a pé, estipula-se 400m, e para distâncias percorridas de bicicleta, 1600m (FARR, 2008; SUZUKI; CERVERO; IUCHI, 2013). Entretanto, essas medidas não podem ser obtidas por meio da relação simples entre a posição da estação e o desenho de um círculo (buffer) que delimite sua área de influência, uma vez que os percursos nas cidades nem sempre se dão em linhas que conectam diretamente dois pontos, mas em função do desenho das 
vias. Assim, é fundamental considerar a rede de ruas em que se dão os deslocamentos para que as distâncias dos percursos sejam precisamente calculadas, o que significa abordar regras de cálculo mais elaboradas.
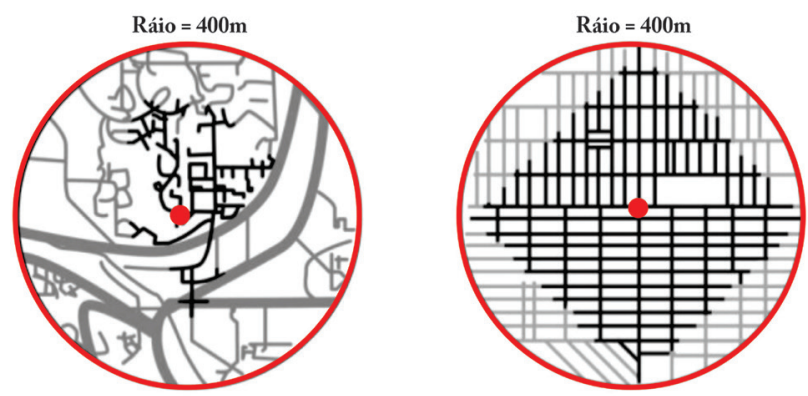

Figura 2 | Diferença entre cálculo das distâncias via buffer (em vermelho), ou considerando a rede de ruas (em preto).

Fonte: Lima, 2017, p. 62.

Há de se considerar ainda que, embora a meta de até $400 \mathrm{~m}$ de distância para o transporte seja comumente aceita, não se pode compreendê-la como um limite rígido. É ilógico supor que alguém que resida a 395m da estação tenha plena acessibilidade ao transporte, enquanto seu vizinho, que vive a $405 \mathrm{~m}$ do mesmo ponto, esteja completamente isolado. Obviamente, a relação entre a distância física e a acessibilidade ao transporte é uma curva contínua, sem interrupções bruscas. Portanto, instrumentos que visem a mensurar $\mathrm{o}$ atendimento a esse princípio devem considerar estas nuances. 
Hillier e Hanson (1984) propõem a teoria da Sintaxe Espacial para descrever as relações espaciais de uma determinada localidade através de medidas quantitativas (ou sintáticas), que possibilitam compreender aspectos importantes do sistema urbano, como a acessibilidade e a distribuição de usos do solo.

Dentre as medidas sintáticas, a principal é chamada integração. Essa medida é utilizada para a previsão de fluxos de pedestres e veículos em um determinado espaço, o que the confere utilidade para o entendimento da dinâmica dos encontros sociais e do posicionamento de diferentes atividades urbanas. A integração mede o quão "profundo", ou distante, um determinado espaço está de todos os outros espaços do sistema. No entanto, o conceito de profundidade considera a distância topológica, e não a distância física. Dessa forma, todos os espaços diretamente conectados estão a um passo topológico entre si. Espaços que se conectem por intermédio de um outro espaço estão a dois passos topológicos de distância, e assim sucessivamente. A profundidade média de um determinado espaço é, por conseguinte, obtida pela somatória das profundidades de todos os demais espaços em relação a ele, dividida pelo número total de espaços menos um.

Uma outra medida sintática a ser considerada no contexto desta pesquisa é a conectividade. Essa medida calcula 
a quantidade de espaços (ou vias, no contexto urbano) que se interceptam. Isso significa que a conectividade pode ser usada para computar quantas conexões diretas com outros espaços (ou ruas) uma determinada via possui, possibilitando compreender sua importância em uma rede. Espaços com alta conectividade tendem a ter um papel estruturador, uma vez que promovem, potencialmente, acesso a um grande número de outros espaços.

\subsection{Métricas para a caminhabilidade}

Diversas estratégias e instrumentos têm sido desenvolvidos no intuito de mensurar a caminhabilidade de um determinado local. Um desses instrumentos é o Walkscore, um algoritmo que, segundo Carr, Dunsigen e Marcus, (2011), gera uma pontuação que se baseia na distância entre uma determinada localidade e os pontos de comércio e serviço mais próximos a ela. Esses pontos classificados em cinco categorias (educacional, alimentação, comércio, entretenimento e recreação), são ponderados com mesmo peso e somados, resultando em um único índice que classifica a caminhabilidade de um determinado local. Por exemplo, se em relação a uma determinada localidade o serviço mais próximo em uma categoria está a 400m (cinco minutos de caminhada ou menos), então o número máximo de pontos é atribuído para esta localidade nessa categoria. O número de pontos diminui à medida que a distância se aproxima de 1,6 km (30 minutos 
de caminhada) e não são atribuídos pontos para serviços com mais de 1,6 km de distância. Cada categoria possui o mesmo peso e os pontos são somados e normalizados para produzir uma pontuação entre 0-100, o que permite classificar a caminhabilidade de uma determinada área (ver Tabela 1). O número de serviços disponíveis e a suas distâncias para as residências nas proximidades são os principais parâmetros para promover a caminhabilidade.

\begin{tabular}{|l|l|}
\hline \multirow{2}{*}{$90-100$} & Walker's paradise \\
\cline { 2 - 2 } & Percursos diários não demandam automóvel \\
\hline $70-89$ & Very walkable \\
\cline { 2 - 2 } & A maioria dos percursos podem ser vencidos a pé. \\
\hline $50-69$ & Somewhat walkable \\
\hline \multirow{2}{*}{$25-49$} & Alguns percursos podem ser vencidos a pé. \\
\hline $0-24$ & Car-dependent \\
\hline & A maioria dos percursos demandam automóvel \\
\hline & Car-dependent \\
\hline
\end{tabular}

Tabela1 | Classificação de valores de Walkscore.

Fonte: (LIMA, 2017, p. 67). Elaborado a partir de Walkscore (2014).

Dobesova e Krivka (2012) utilizam o Walkability Index, um outro instrumento que visa a mensurar a caminhabilidade de uma determinada área. Para isso, esse indicador considera quatro subíndices que avaliam diferentes aspectos relacionados à caminhabilidade, são eles: (a) Conectivity Index - também denominado Intersection Index, esse subíndice, que adapta medidas da teoria da sintaxe espacial, calcula o número de interseções entre ruas por metro 
quadrado de uma determinada área, de maneira a procurar indicar quão conectada uma determinada vizinhança é; (b) Entropy Index - visa mensurar o quão diverso é o uso de uma determinada área, ao quantificar diferentes funções em uma área urbana, de acordo com as seguintes categorias: residencial, comercial, serviços, industrial, institucional, e outros; (c) Floor Area Ratio Index - considera a proporção entre as áreas de cada serviço e a área total de sua respectiva categoria; (d) Household density index - informa a densidade populacional de uma determinada localidade com base no número de domicílios.

Existem ainda inúmeros índices e instrumentos que visam mensurar características relacionadas à caminhabilidade de uma determinada localidade. Alguns abordam, inclusive, questões subjetivas, relacionadas à percepção do pedestre (ZACHARIAS, 2001; ZAMPIERI, 2006, entre outros). Entretanto, considerando o espectro de interesse e os objetivos de aplicação desta investigação, os dois índices apresentados (Walkscore e Walkability Index) são alvo de especial atenção por tratarem aspectos objetivos e essencialmente mensuráveis, que podem servir de referência para o desenvolvimento de métricas e instrumentos que permitam medir e otimizar o desempenho de configurações urbanas com base em aspectos objetivos. 


\subsection{Métricas para a diversidade}

Hoek (2008) propõe um indicador que visa a mensurar quão diversificada uma determinada área urbana é. Trata-se do Mixed-Use Index (MXI), que calcula a proporção entre a soma de todas as áreas residenciais e não residenciais de um bairro, realizando uma comparação dessas proporções, conforme demonstrado na Tabela 2. Quanto mais próxima a relação entre as áreas é de 50/50, maior a diversidade que uma área urbana possui.

\begin{tabular}{|c|c|c|c|}
\hline \multicolumn{1}{|c|}{ MXI } & 0 & 50 & 100 \\
\hline Significado & Não residencial & Equilibrio 50/50 & Residencial \\
\hline Tipo & Monofuncional & Uso misto & Monofuncional \\
\hline Exemplos & Complexo Industrial & Centro da Cidade & Subúrbio \\
\hline
\end{tabular}

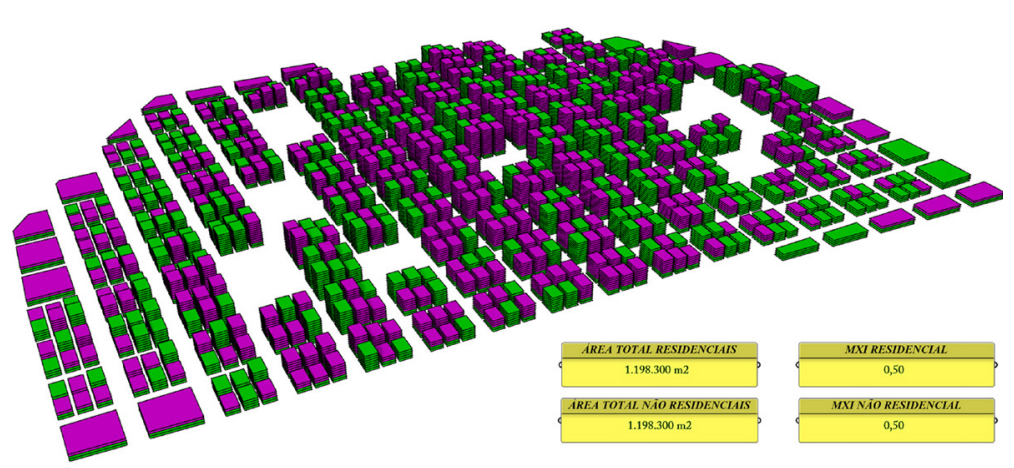

Figura 3 | Exemplo de uma área urbana com pleno equilíbrio entre áreas residenciais e não-residenciais.

Fonte: Lima, 2017, p. 142. 


\subsection{Métricas para a compacidade}

Pont e Haupt (2010) propõem uma abordagem de múltiplas variáveis para medição de diferentes indicadores de densidade, o Spacematrix. Esse conjunto de índices objetiva oferecer um método específico o suficiente para permitir a análise de tipos urbanos e o gerenciamento de quantidades excessivas de dados sem, no entanto, estabelecer definições excessivamente detalhadas.

O Spacematrix consiste em três indicadores fundamentais: Intensidade (Floor Space Index - FSI), Cobertura (Ground Space Index - GSI) e Densidade da rede (Network density - M. O FSI reflete a intensidade de construção e é dado pela divisão entre a área total construída e a área do local que se analisa. O GSI demonstra a relação entre espaços construídos e não construídos e é calculado por meio da razão entre a área ocupada no solo e a área do local que se analisa. $\mathrm{N}$ se refere à concentração de redes em um dado tecido, e é obtido por meio da divisão entre o somatório da extensão das ruas internas com a metade do perímetro das ruas que delimitam uma área, adicionada a área total do local que se analisa (PONT; HAUPT, 2010). Os indicadores de Spacematrix são instrumentos dinâmicos que fornecem avaliações objetivas das questões de densidade e podem ser adaptados à diversas escalas urbanas (edifício, lote, quadra, tecido e bairro), o que os credenciam como um importante instrumento no 
escopo desta investigação.

\section{Considerações finais}

Planejar as cidades para uma organização eficiente é a maneira mais eficaz e sustentável para reduzir os impactos da lógica atual de mobilidade nas cidades e promover uma vida mais interativa nos centros urbanos. Nesse quadro, o DOT é um modelo em franco desenvolvimento ao redor do mundo, que se baseia em alguns princípios mensuráveis para melhorar a organização (sob a perspectiva da mobilidade urbana e do uso do solo sustentáveis) de bairros e cidades, por meio de uma ordenação urbana que preconiza a proximidade ao transporte e a demais serviços essenciais, a distribuição equilibrada de atividades e a compactação e o adensamento dos centros urbanos. Nesse contexto, esse trabalho apresenta além de uma revisão de literatura sobre o tema uma articulação de princípios básicos mensuráveis do DOT e de suas respectivas métricas para análise. Pretende-se, portanto, contribuir para o desenvolvimento de abordagens de projeto e planejamento urbano que se beneficiem da utilização de princípios e métricas objetivamente quantificáveis para avaliação e proposição de configurações urbanas mais autônomas e sustentáveis.

No que diz respeito a esse cenário, é importante reforçar que o DOT se apoia em princípios essencialmente 
mensuráveis como estratégia para qualificar a vida urbana, auxiliando na proposição de cidades mais dinâmicas, caminháveis, compactas e diversas. Em outras palavras, o DOT constitui uma base teórica e prática com inúmeras possibilidades para exploração e para implementação, que pode ser suportada, por exemplo, por recursos e ferramentas computacionais. Por essa razão, as bases do DOT podem ser adotadas como referência para o desenvolvimento de novas ferramentas e abordagens, que visem a suportar tarefas de análise urbana e de tomada de decisão. Além disso, é importante ressaltar que ainda não foram suficientemente desenvolvidas abordagens que considerem a grande quantidade de parâmetros (e de dados) que podem estar envolvidos no contexto do DOT para suportar maneiras de implementação mais dinâmicas e eficientes. Trata-se, portanto, de um modelo que pode ser em grande parte programável, o que o credencia como um caso potencial para implementação de recursos computacionais. Apesar de grande parte da base teórica desta pesquisa, bem como muito dos referenciais dos princípios e métricas apresentadas serem mais constantemente implementadas em uma realidade urbana diferente da brasileira, acreditamos que o uso da parametrização possui potencial para as adequações que se façam necessárias sejam dinamicamente abordadas para soluções dos principais problemas de nossas cidades, dentre eles habitação, saúde e mobilidade urbana. 
Por fim, acreditamos que este artigo possa contribuir para o desenvolvimento de novas abordagens e/ou instrumentos de planejamento orientados pelo DOT e por seus princípios, de maneira a identificar métricas que possam ser sistematizadas e implementadas como base para avaliação e implementação de projetos orientados em um contexto paramétrico. Espera-se, em trabalhos futuros, a elaboração e o aprimoramento de ferramentas nesse sentido, assim como a identificação de mais métricas que possam se relacionar com os princípios apontados neste trabalho e até mesmo com novos princípios que extrapolem o conceito de DOT, mas que possam contribuir para a consolidação de cidades mais compactas, autônomas, sustentáveis e dinâmicas.

\section{Agradecimentos}

Agradecemos ao Conselho Nacional de Desenvolvimento Científico e Tecnológico (CNPq), ao Centro de Investigação em Arquitectura, Urbanismo e Design (CIAUD) da Universidade de Lisboa e ao Programa de Pós-Graduação em Urbanismo (PROURB) da Universidade Federal do Rio de Janeiro (UFRJ), pelo suporte concedido para o desenvolvimento desta pesquisa.

\section{Referências}

ALTOON, R.; AULD, J. Urban Transformations: Transit Oriented Development \& The Sustainable City. Mulgrave: 
The Images Publishing Group, 2011.

CALTHORPE, P. The next American metropolis: Ecology, community and the American dream. New York: Princeton Architectural Press, 1993.

CALTHORPE, P.; FULTON, W. The regional city: planning for the end of sprawl. Washington, DC: Island Press, 2001.

CARR, L.; DUNSIGEN, I.; MARCUS, B. Validation of walk score for estimating access to walkable amenities. British journal sports medicine, v. 45, p. $1144-1158,2011$.

CERVERO, R.; KOCKELMAN, K. Travel demand and the 3Ds: density, diversity, and design. Transportation Research Part D: Transport and Environment, v. 2, p. 199219, 1997.

CHAKRABARTI, V. A country of cities. New York, NY, USA: Metropolis Books, 2013.

DANTZIG, G.; SAATY, T. Compact City: A plan for a liveable urban environment. San Francisco: W. H. Freeman, 1973.

DITTMAR, H.; OHLAND, G. (EDS.). The new transit town: Best practices in Transit-Oriented Development. Washington, DC: Island Press, 2004.

DOBESOVA, Z.; KRIVKA, T. Walkability Index in the Urban 
Planning: A Case Study in Olomouc City. In: BURIAN, J. (Ed.). Advances in Spatial Planning. Rijeka: InTech, 2012. p. $179-196$.

FARR, D. Sustainable Urbanism: Urban Design With Nature. Hoboken, NJ: John Willey and sons, 2008.

GEHL, J. Cidades para pessoas. São Paulo: Perspectiva, 2013.

GLAESER, E. Os centros urbanos: a maior invenção da humanidade: como as cidades nos tornam mais ricos, inteligentes, saudáveis e felizes. [s.I.] Elsevier, 2011. Global Fuel Economy. Disponível em: <http://www.globalfueleconomy.org/>. Acesso em: 4 out. 2016.

HILLIER, B.; HANSON, J. The social logic of space. Cambridge: Cambridge University Press, 1984.

HOEK, J. The MXI (Mixed use Index). An instrument for anti-sprawl policy? Proceedings of the 44th ISOCARP congress. Anais... In: 44TH ISOCARP CONGRESS. 2008

LEITE, C. Cidades sustentáveis cidades inteligentes: Desenvolvimento sustentável num planeta urbano. Porto Alegre: Bookman, 2012.

LIMA, F. Metricas Urbanas: Sistema (para)métrico para análise e otimização de configurações urbanas. [s.I.] Uni- 
versidade Federal do Rio de Janeiro, 28 abr. 2017.

LIMA, F.; PARAÍZO, R. C.; KÓS, J. R. Algorithms-Aided Sustainable Urban Design: Geometric and Parametric Tools for Transit-Oriented Development. In: AMORUSO, G. (Ed.). Handbook of Research on Visual Computing and Emerging Geometrical Design Tools. Hershey: |G| Global, 2016a. p. 875-897.

LIMA, F.; PARAÍZO, R. C.; KÓS, J. R. Algorithmic approach towards Transit-Oriented Development neighborhoods: (Para)metric tools for evaluating and proposing rapid transit-based districts. International Journal of Architectural Computing, v. 14, n. 2, p. 131-146, 1 jun. 2016b.

OGRA, A.; NDBELE, R. The role of 6 ds in transit-oriented development (TOD). (S. Bahga, A. Singla, Eds.) Proceedings of the Neo-International Conference on Habitable Environments. Anais... In: NEO-INTERNATIONAL CONFERENCE ON HABITABLE ENVIRONMENTS. Jalandhar, India: 2014

PANERAI, P.; CASTEX, J.; DEPAULE, J. Formas urbanas: a dissolução da quadra. Porto Alegre: Bookman, 2013.

PATEL, I.; SHAH, J. A Review Study on Transit Oriented Development (TOD) Index by using Different Criteria. Global Research and Development Journal for Engineering, p. 137-140, 2019. 
PONT, M.; HAUPT, P. Spacematrix: Space, Density and Urban Form. Rotterdam: NAi Publishers, 2010.

RODRIGUES, J. Qual o estado da mobilidade urbana no Brasil? In: PAULA, M.; BARTELT, D. (Eds.). Mobilidade urbana no Brasil: desafios e alternativas. Rio de Janeiro: FUNDAÇÃO HEINRICH BÖLL BRASIL, 2016. p. 12-23.

ROGERS, R. Cidades para um pequeno planeta. BarceIona: Gustavo Gili, 1997. SÃO PAULO. 16.050. Plano Diretor Estratégico do Município de São Paulo - Lei no 16.050, de 31 de julho de 2014 - Estratégias ilustradas. São Paulo: Prefeitura de São Paulo. 2014, p. 76.

STUCHI, F.; LEITE, C. Plano de desenvolvimento urbano estratégico de Nova Friburgo 2050. Disponível em: <http://www.stuchileite.com>. Acesso em: 22 set. 2015.

SUZUKI, H.; CERVERO, R.; IUCHI, K. Transforming Cities with Transit: Transit and Land-Use Integration for Sustainable Urban Development. Washington, DC: World Bank, 2013.

TRANSIT COOPERATIVE RESEARCH PROGRAM. Transit-Oriented Development in the United States: Experiences, Challenges, and Prospects. Washington, DC

ZACHARIAS, J. Pedestrian Behavior and Perception in the Urban Walking Environments. Journal of Planning Lite- 
rature, v. 16, n. 1, p. 3-18, 2001.

ZAMPIERI, F. Modelo Estimativo de Pedestres Baseado em Sintaxe Espacial, Medidas de Desempenho e Redes Neurais Artificiais. Dissertação de Mestrado Porto Alegre: UFRGS, 2006. 